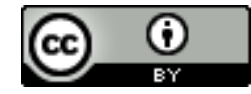

Esta obra está sob o direito de Licença Creative Commons Atribuição 4.0 Internacional.

\title{
A INFLUÊNCIA DA RELAÇÃO ENTRE SANEAMENTO BÁSICO E SAÚDE PÚBLICA NO COMBATE À DISSEMINAÇÃO DO COVID-19
}

\author{
Marcelo Lucas Alves ${ }^{1}$ \\ Maria Clara da Rocha dos Santos Silva ${ }^{2}$ \\ Maria Eduarda Melo Calado 3 \\ Matheus Henrique Alves da Silva ${ }^{4}$ \\ Nivea Tavares da Silva \\ Paulo Bruno Silva Santos 6
}

\section{RESUMO}

As questões relacionadas à saúde, higiene e meio ambiente envolvem grande parte da população mundial. No Brasil, a falta de acesso aos serviços básicos atinge principalmente os mais pobres, concentrados em favelas, periferias urbanas e áreas rurais. A falta ou ineficiência dos serviços de saúde tem agravado a saúde e a qualidade de vida das pessoas. Portanto, a falta de investimento neste setor tem um impacto negativo no sistema econômico devido ao saneamento básico e aos altos gastos com a prevenção e o tratamento da transmissão de doenças. Com base no texto supracitado o presente trabalho se propõe a avaliar por meio de uma revisão sistemática integrativa a relação entre saneamento básico e saúde pública no combate à disseminação do COVID-19. Analisaram-se os artigos publicados na base de dados da plataforma CAPES entre os anos de 2015 e 2020, sobre saneamento básico, saúde pública, esgotamento sanitário e covid19, adotando alguns critérios de inclusão e exclusão. A busca resultou em dez artigos de relevância para o contexto e a problemática proposta, que foram explorados e discutidos. Portanto, é de suma importância o investimento em saneamento básico acarretando assim menos gastos e superlotações na saúde pública, além de diminuir a disseminação de doenças de veiculação hídrica.

Palavras-chave: Esgotamento sanitário. Saúde Pública. SARS-CoV-2. Pandemia.

\footnotetext{
1 apolo273_my@hotmail.com

2 clara_rochha@outlook.com

3 eduardamelocallado@gmail.com

${ }^{4}$ henrique321santos@hotmail.com

5 niveatavares84@hotmail.com

${ }^{6}$ paulobruno1373@gmail.com
} 


\section{INTRODUÇÃO}

Após quase duas décadas de falta de regulamentação e ordenamento jurídico, foi aprovada a Lei 11.445 e estabelecidas as diretrizes nacionais para instalações de saneamento básico, que hoje é considerado um conjunto de ações de abastecimento de água (AA), esgotamento sanitário (ES), manejo de resíduos sólidos (MRS) e manejo das águas pluviais (MAP), bem como definição de outros conteúdos importantes (MENEZES, 2014).

Na gestão do sistema de saúde mundial de hoje, a pandemia COVID-19 é o foco da atenção contemporânea. Desde o surto no final de 2019, com a rápida propagação da epidemia em Hubei, China, essa nova síndrome respiratória se espalhou por todos os cantos do mundo a um ritmo alarmante (DA SILVEIRA, 2020).

A COVID-19 é uma doença infecciosa que tem como agente causador 0 coronavírus denominado SARS-CoV-2. Pesquisas científicas apontam que a disseminação do COVID-19 de pessoa para pessoa ocorre principalmente pela via respiratória. Porem recentemente foi encontrado o vírus nas fezes de indivíduos infectados, com ou sem sintomas (PÊGO, 2020).

Embora tal panorama tenha origem sanitária, ele também agrava os problemas sociais em diferentes ordens ao tangenciar problemas relacionados às condições de moradia, alimentação, trabalho, renda e acesso a bens de consumo. Portanto, o desafio que se apresenta vai além do setor saúde. Porém, no âmbito da gestão do sistema de saúde, o desafio é prioritário, exigindo a competência técnica e capacidade política de seus representantes e equipes para mitigar o impacto da pandemia em cada localidade (QUINTSLR, 2020).

A falta ou ineficiência dos serviços de saneamento tem agravado a saúde e a qualidade de vida das pessoas. Logo, é possível perceber que a falta de entrega neste setor gera um impacto extremamente negativo na economia. Este artigo tem como objetivo analisar até que nível a relação entre saneamento básico e saúde pública influencia no combate à disseminação do COVID-19. De modo que, torna-se necessário a atuação de políticas públicas que busquem expandir os serviços de saneamento, essencialmente para as localidades com situações mais precárias. 


\section{METODOLOGIA}

A metodologia adotada no presente trabalho trata-se de uma revisão sistemática integrativa que teve como base de buscas a plataforma de periódicos CAPES, utilizando-se os descritores saneamento básico, saúde pública, esgotamento sanitário e covid-19 conectados pelo conector booleano "And".

Para o escopo deste estudo, consideraramse como critérios de inclusão: Artigos publicados entre 2015 e 2020, que respondiam à pergunta norteadora e atendiam a temática estabelecida pelos descritores, em língua portuguesa. Foram excluídos artigos que não contemplam a temática. Criou-se um fichamento protocolar contemplando: títulos, ano, autor, palavras chave e tipo de pesquisa. O Quadro 1 demonstra como os descritores foram utilizados e a quantidade de estudos localizados na base de dados, assim como detalhamentos como o cadastro dos descritores nos bancos de terminologias, tema, objetivo, pergunta norteadora, entre outros. 
Quadro 1 - Detalhamento das etapas da Revisão Sistemática Integrativa.

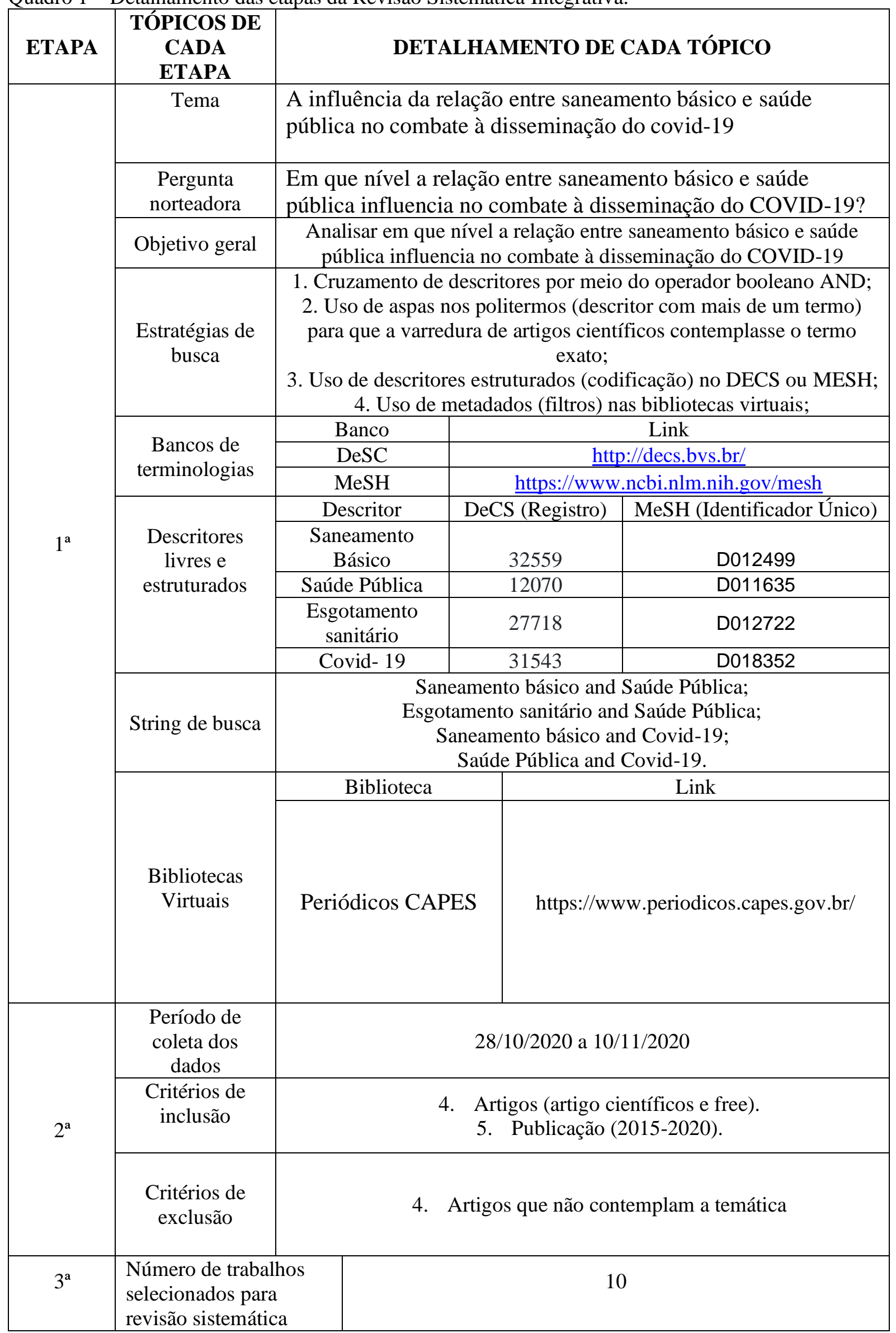




\begin{tabular}{|c|l|l|}
\hline & $\begin{array}{l}\text { integrativa a partir da } \\
\text { leitura dos agentes } \\
\text { indexadores das } \\
\text { publicações (tema, } \\
\text { descrição, ementa). }\end{array}$ & \\
\hline $4^{\mathrm{a}}$ & $\begin{array}{l}\text { Categorias obtidas com } \\
\text { a análise dos } \\
\text { documentos } \\
\text { investigados online } \\
\text { gratuitos e de livre } \\
\text { acesso }\end{array}$ \\
\hline $5^{\mathrm{a}}$ & $\begin{array}{l}\text { Análise, interpretação e } \\
\text { discussão dos } \\
\text { resultados }\end{array}$ & \\
\hline $6^{\mathrm{a}}$ & $\begin{array}{l}\text { Apresentação da } \\
\text { revisão em formato de } \\
\text { artigo, o qual } \\
\text { contemple propostas } \\
\text { para estudos futuros }\end{array}$ & \\
\hline
\end{tabular}

Fonte: elaborada pelos autores.

\section{RESULTADOS}

O detalhamento sobre as strings de busca utilizadas na base de dados do Periódico CAPES e os respectivos dados quantitativos sobre os resultados dos artigos nas buscas estão dispostos no Quadro 2. Dentro dessa perspectiva, a string com maior quantidade de artigos encontrados dentro da temática foi "Saneamento básico And Saúde pública", com o total de 691 trabalhos, sendo que, desses, apenas 4 selecionados para compor os resultados e discussão.

Quadro 2 - Corresponde ao total de documentos disponíveis na Plataforma obtidos por string de busca.

\begin{tabular}{|l|c|c|c|c|}
\hline \multicolumn{1}{|c|}{ String de busca } & $\begin{array}{c}\text { Bases de } \\
\text { dados }\end{array}$ & $\begin{array}{c}\text { Total de } \\
\text { publicações } \\
\text { sem o filtro }\end{array}$ & $\begin{array}{c}\text { Publicações } \\
\text { disponíveis após } \\
\text { aplicar os filtros }\end{array}$ & $\begin{array}{c}\text { Publicações } \\
\text { aproveitadas na } \\
\text { Revisão Sistemática } \\
\text { Integrativa }\end{array}$ \\
\hline $\begin{array}{l}\text { Saneamento Básico } \\
\text { And Saúde Pública }\end{array}$ & $\begin{array}{c}\text { Periódico } \\
\text { CAPES }\end{array}$ & 691 & 253 & 4 \\
\hline $\begin{array}{l}\text { Esgotamento } \\
\text { Sanitário And } \\
\text { Saúde Pública }\end{array}$ & $\begin{array}{c}\text { Periódico } \\
\text { CAPES }\end{array}$ & 180 & 87 & 2 \\
\hline $\begin{array}{l}\text { Saneamento básico } \\
\text { And Covid-19 }\end{array}$ & $\begin{array}{c}\text { Periódico } \\
\text { CAPES }\end{array}$ & 3 & 3 & 1 \\
\hline $\begin{array}{l}\text { Saúde Pública And } \\
\text { Covid-19 }\end{array}$ & $\begin{array}{c}\text { Periódico } \\
\text { CAPES }\end{array}$ & 128 & 102 & 3 \\
\hline
\end{tabular}

Fonte: elaborada pelos autores. 
O Quadro 3 trás o detalhamento dos 10 (dez) artigos selecionados após a aplicação dos critérios de inclusão e exclusão, assim como, avaliação técnica dos artigos. O Quadro mostra a autoria, o tema, o link e a data de publicação e a conclusão dos artigos.

Quadro 3- Descrição dos documentos (artigos) de acordo com os critérios de inclusão.

\begin{tabular}{|c|c|c|c|c|c|}
\hline $\mathbf{N}^{\mathbf{o}}$ & Autor(a) & Tema & $\begin{array}{c}\text { Link da } \\
\text { publicação }\end{array}$ & $\begin{array}{c}\text { Data de } \\
\text { publicação }\end{array}$ & Conclusão \\
\hline 1 & $\begin{array}{l}\text { Fernanda } \\
\text { Flores } \\
\text { Silva } \\
\text { Dos } \\
\text { Santos. }\end{array}$ & $\begin{array}{l}\mathrm{O} \\
\text { desenvolvimen } \\
\text { to do } \\
\text { saneamento } \\
\text { básico no } \\
\text { Brasil e as } \\
\text { consequências } \\
\text { para a saúde } \\
\text { pública }\end{array}$ & $\begin{array}{l}\text { https://bityli.co } \\
\text { m/cK3hp }\end{array}$ & 01/10/2018 & $\begin{array}{l}\text { Apesar do grande volume } \\
\text { de recursos públicos } \\
\text { investidos no setor de } \\
\text { saneamento, a situação do } \\
\text { País demonstra que há um } \\
\text { grande atraso na } \\
\text { universalização destes } \\
\text { serviços, de modo que } \\
\text { este já devia ter sido } \\
\text { atingido estar compatível } \\
\text { com o desenvolvimento } \\
\text { econômico alcançado nos } \\
\text { últimos anos. } \\
\text { O saneamento básico é } \\
\text { um direito de necessidade } \\
\text { imediata, pois, sua } \\
\text { ausência ou deficiência } \\
\text { influencia negativamente } \\
\text { no meio ambiente, na } \\
\text { qualidade de vida e saúde } \\
\text { da população, sendo } \\
\text { inadmissível pensar a } \\
\text { existência de uma } \\
\text { sociedade em } \\
\text { desenvolvimento sem esta } \\
\text { prestar serviços básicos } \\
\text { em quantidade e qualidade } \\
\text { suficiente, como o } \\
\text { saneamento [...] }\end{array}$ \\
\hline 2 & $\begin{array}{c}\text { Priscila } \\
\text { Neves } \\
\text { Silva }\end{array}$ & 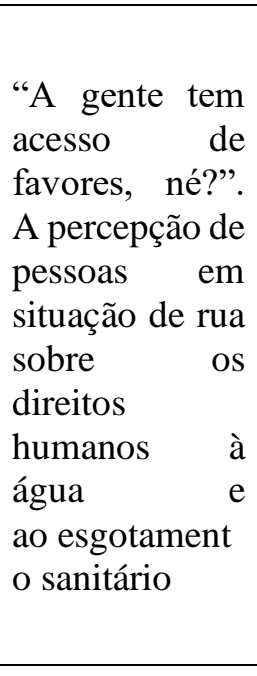 & $\begin{array}{l}\text { https://bityli.co } \\
\text { m/B0QSW }\end{array}$ & 01/03/2018 & $\begin{array}{l}\text { Observa-se que a população } \\
\text { em situação de rua sofre } \\
\text { diferentes tipos de violações } \\
\text { dos DHAES, assim como de } \\
\text { outros direitos, como o direito } \\
\text { à cidade, à moradia e à saúde. } \\
\text { A violação desses direitos } \\
\text { tem repercussões negativas } \\
\text { na vida econômica e social } \\
\text { desse grupo populacional, } \\
\text { aumentando a discriminação } \\
\text { e a exclusão. Assim, é } \\
\text { importante promover o } \\
\text { reconhecimento do acesso à } \\
\text { água e ao saneamento como }\end{array}$ \\
\hline
\end{tabular}




\begin{tabular}{|c|c|c|c|c|c|}
\hline & & & & & $\begin{array}{l}\text { direito, por parte do Estado. } \\
{[\ldots]}\end{array}$ \\
\hline 3 & $\begin{array}{c}\text { Luís } \\
\text { Paulo } \\
\text { Souza e } \\
\text { Souza }\end{array}$ & $\begin{array}{l}\text { Presença do } \\
\text { novo } \\
\text { coronavírus } \\
\text { (SARS-CoV- } \\
\text { 2) nos esgotos } \\
\text { sanitários: } \\
\text { apontamentos } \\
\text { para ações } \\
\text { complementar } \\
\text { es de vigilância } \\
\text { à saúde em } \\
\text { tempos de } \\
\text { pandemia }\end{array}$ & $\begin{array}{l}\text { https://bityli.co } \\
\text { m/tp5tc }\end{array}$ & $01 / 06 / 2020$ & $\begin{array}{l}\text { Apesar de, até o momento, } \\
\text { nenhuma pesquisa confirmar } \\
\text { a } \\
\text { transmissão da COVID-19 } \\
\text { pela via fecal-oral, os estudos } \\
\text { aqui apresentados sinalizam a } \\
\text { importância de incluir esta } \\
\text { temática na pauta de } \\
\text { discussões frente à pandemia. } \\
\text { No Brasil, mesmo com as } \\
\text { dificuldades relativas ao } \\
\text { saneamento, os esgotos } \\
\text { podem ser mais uma } \\
\text { ferramenta capaz de } \\
\text { contribuir nos esforços das } \\
\text { vigilâncias sanitária, } \\
\text { ambiental e epidemiológica. } \\
\text { Torna-se essencial que o } \\
\text { Estado amplie o sistema de } \\
\text { esgotamento sanitário para a } \\
\text { população, além de adotar } \\
\text { medidas que estimulem e } \\
\text { exijam das empresas } \\
\text { prestadoras dos serviços de } \\
\text { saneamento o alinhamento de } \\
\text { suas atuações, com a } \\
\text { necessidade de que elas } \\
\text { tenham controle sobre os } \\
\text { sistemas, para que sejam } \\
\text { fornecidos dados de } \\
\text { qualidade e capazes de } \\
\text { orientar medidas preventivas } \\
\text { de contágio e mitigação dos } \\
\text { riscos de adoecimento. [...] }\end{array}$ \\
\hline 4 & $\begin{array}{l}\text { Davi } \\
\text { Santiago } \\
\text { Aquino }\end{array}$ & $\begin{array}{l}\text { Influência do } \\
\text { acesso a } \\
\text { saneamento } \\
\text { básico na } \\
\text { incidência e na } \\
\text { mortalidade } \\
\text { por COVID- }\end{array}$ & $\begin{array}{l}\text { https://bityli.co } \\
\text { m/53OyN }\end{array}$ & $01 / 10 / 2020$ & $\begin{array}{l}\text { Ao se analisarem os dados } \\
\text { mais recentes de acesso das } \\
\text { populações das unidades } \\
\text { federativas do Brasil aos } \\
\text { serviços de abastecimento de } \\
\text { água e de esgotamento } \\
\text { sanitário, bem como as taxas }\end{array}$ \\
\hline
\end{tabular}




\begin{tabular}{|c|c|c|c|c|c|}
\hline & & $\begin{array}{l}\text { 19: análise de } \\
\text { regressão } \\
\text { linear múltipla } \\
\text { nos estados } \\
\text { brasileiros. }\end{array}$ & & & $\begin{array}{l}\text { de incidência e de } \\
\text { mortalidade por COVID-19 } \\
\text { registradas nos estados e no } \\
\text { Distrito Federal } 90 \text { dias após } \\
\text { a confirmação do primeiro } \\
\text { caso da doença no país, } \\
\text { verificou-se a existência de } \\
\text { influência linear } \\
\text { estatisticamente significativa } \\
\text { das variáveis relativas a } \\
\text { saneamento básico na } \\
\text { incidência acumulada, de } \\
\text { forma que quanto maior o } \\
\text { acesso aos serviços de } \\
\text { saneamento, menor a } \\
\text { incidência de COVID-19. [...] }\end{array}$ \\
\hline 5 & $\begin{array}{l}\text { Luis } \\
\text { Arthur } \\
\text { Brasil } \\
\text { Gadelha } \\
\text { Farias }\end{array}$ & $\begin{array}{l}\text { O papel da } \\
\text { atenção } \\
\text { primária no } \\
\text { combate ao } \\
\text { Covid-19: } \\
\text { impacto na } \\
\text { saúde pública e } \\
\text { perspectivas } \\
\text { futuras }\end{array}$ & $\begin{array}{c}\text { https://bityli.co } \\
\text { m/tIw3G }\end{array}$ & $01 / 05 / 2020$ & $\begin{array}{l}\text { Desta forma, a APS deve ser } \\
\text { a porta de entrada deste } \\
\text { paciente no sistema de saúde. } \\
\text { Uma vez que essa atenção } \\
\text { primária esteja bem equipada } \\
\text { e integrada terá papel } \\
\text { fundamental no controle e na } \\
\text { redução de danos causados } \\
\text { pela pandemia pelo Covid-19. } \\
\text { Neste momento, a melhor } \\
\text { ferramenta de controle } \\
\text { existente para o Covid-19 é a } \\
\text { prevenção e não existe } \\
\text { melhor lugar para } \\
\text { desenvolvê-la do que na APS. } \\
\text { Logo, é necessária a garantia } \\
\text { do bom funcionamento da } \\
\text { APS por meio da valorização } \\
\text { da ESF, o que envolve um } \\
\text { melhor fortalecimento deste } \\
\text { nível de atenção, incluindo a } \\
\text { garantia de condições dignas } \\
\text { de trabalho e de assistência. } \\
\text { Importante destacar que, } \\
\text { dentre essas condições, é } \\
\text { fundamental o provimento de } \\
\text { EPI's adequados e em } \\
\text { quantidade necessária para } \\
\text { que os profissionais possam } \\
\text { ter segurança em sua atuação } \\
\text { e, consequentemente, } \\
\text { protegerem seus pacientes. }\end{array}$ \\
\hline 6 & $\begin{array}{l}\text { Daniela } \\
\text { Borcezi }\end{array}$ & $\begin{array}{l}\text { VULNERÁV } \\
\text { EIS }\end{array}$ & $\begin{array}{c}\text { https://bityli.co } \\
\text { m/QBzTs }\end{array}$ & $01 / 09 / 2020$ & $\begin{array}{l}\text { [...] Ao contrário disso, as } \\
\text { reportagensVulnerabilidades } \\
\text { que aproximas as Favelas } \\
\text { contra o vírus, nos revelam }\end{array}$ \\
\hline
\end{tabular}




\begin{tabular}{|c|c|c|c|c|c|}
\hline & & & & & $\begin{array}{l}\text { narrativas pautadas no } \\
\text { "homem comum" e na } \\
\text { ausência de políticas públicas } \\
\text { sociais em meio a pandemia } \\
\text { da covid-19. [...] }\end{array}$ \\
\hline 7 & $\begin{array}{c}\text { Michael } \\
\text { Ferreira } \\
\text { Machado }\end{array}$ & $\begin{array}{l}\text { Vigilância } \\
\text { em Saúde em } \\
\text { tempos de } \\
\text { pandemia: } \\
\text { análise dos } \\
\text { planos de } \\
\text { contingência } \\
\text { dos estados } \\
\text { do Nordeste }\end{array}$ & $\begin{array}{c}\text { https://bityli.co } \\
\text { m/9hhRc }\end{array}$ & $01 / 06 / 2020$ & $\begin{array}{l}\text { A pandemia da COVID-19 } \\
\text { trouxe uma série de desafios } \\
\text { ao SUS na produção de } \\
\text { respostas articuladas e } \\
\text { efetivas para a proteção da } \\
\text { população brasileira. Neste } \\
\text { âmbito, os aspectos político- } \\
\text { institucionais e de articulação } \\
\text { da Vigilância em Saúde são } \\
\text { fundamentais. A atuação } \\
\text { integrada e compartilhada da } \\
\text { Vigilância em Saúde nos } \\
\text { diversos níveis de governo } \\
\text { está prevista no arcabouço } \\
\text { normativo do SUS. No } \\
\text { contexto nordestino, além da } \\
\text { heterogeneidade dos } \\
\text { municípios, há que considerar } \\
\text { ainda fragilidades } \\
\text { institucionais na gestão local } \\
\text { do sistema de saúde, visto que } \\
\text { a região Nordeste concentra } \\
\text { 63,4\% de municípios do } \\
\text { grupo de pequeno porte do } \\
\text { país. [...] }\end{array}$ \\
\hline 8 & $\begin{array}{l}\text { Tatiana } \\
\text { Santana } \\
\text { Timóteo } \\
\text { Pereira }\end{array}$ & $\begin{array}{l}\text { Planos } \\
\text { municipais de } \\
\text { saneamento } \\
\text { básico: } \\
\text { avaliação de } 18 \\
\text { casos } \\
\text { brasileiros }\end{array}$ & $\begin{array}{l}\text { https://bityli.co } \\
\text { m/Z2Uh1 }\end{array}$ & 01/09/2015 & $\begin{array}{l}\text { Alguns dos planos avaliados } \\
\text { destacaram-se por terem } \\
\text { atendido de forma geral à } \\
\text { maioria das categorias: } \\
\text { Alagoinhas, Morada Nova, } \\
\text { Ariquemes e Ouro Branco. } \\
\text { Também foram esses os que } \\
\text { tiveram os processos mais } \\
\text { participativos e que adotaram } \\
\text { algumas técnicas de } \\
\text { planejamento. } \\
\text { constatação leva a reforçar a } \\
\text { hipótese que quanto mais } \\
\text { participativo o processo mais } \\
\text { informações se agregam ao } \\
\text { plano, possibilitando a } \\
\text { incorporação das demandas, e } \\
\text { maior a possibilidade de ser } \\
\text { implementado e interferir na } \\
\text { qualidade do saneamento do } \\
\text { município. Esses quatro } \\
\text { planos foram elaborados para } \\
\text { os quatro componentes do }\end{array}$ \\
\hline
\end{tabular}




\begin{tabular}{|c|c|c|c|c|c|}
\hline & & & & & $\begin{array}{l}\text { saneamento e também foram } \\
\text { aprovados por lei. [...] }\end{array}$ \\
\hline 9 & $\begin{array}{l}\text { Ana } \\
\text { Cristina } \\
\text { A. de } \\
\text { Souza }\end{array}$ & $\begin{array}{l}\text { Política de } \\
\text { saneamento } \\
\text { básico no } \\
\text { Brasil: } \\
\text { discussão de } \\
\text { uma trajetória }\end{array}$ & $\begin{array}{l}\text { https://bityli.co } \\
\text { m/9vwTz }\end{array}$ & $01 / 09 / 2016$ & $\begin{array}{l}\text { Este estudo partiu do } \\
\text { princípio de que a política } \\
\text { pública de saneamento é, } \\
\text { acima de tudo, afetada por } \\
\text { atores, interesses e } \\
\text { instituições que permitiriam } \\
\text { explicar o baixo desempenho } \\
\text { observado nas últimas } \\
\text { décadas. Sem a intenção de } \\
\text { esgotar o debate, o trabalho } \\
\text { tentou identificar os } \\
\text { principais atores e as } \\
\text { conjunturas críticas que } \\
\text { configuraram a arena } \\
\text { decisória desse setor no } \\
\text { Brasil. A utilização da } \\
\text { categoria dependência de } \\
\text { trajetória possibilitou } \\
\text { identificar a matriz histórica } \\
\text { da estrutura e da inércia da } \\
\text { configuração política recente } \\
\text { do setor de saneamento no } \\
\text { país, iniciada a partir da } \\
\text { imposição do Planasa em } \\
\text { 1971. O arranjo instituído } \\
\text { pelo Planasa produziu } \\
\text { retornos positivos de ordem } \\
\text { política e econômica que } \\
\text { reforçaram uma trajetória } \\
\text { essencialmente marcada pela } \\
\text { dominância dos grupos } \\
\text { estadualistas e de suas } \\
\text { instituicões no setor. [...] }\end{array}$ \\
\hline 10 & $\begin{array}{l}\text { Irene } \\
\text { Patrícia } \\
\text { Nohara }\end{array}$ & $\begin{array}{l}\text { Perspectivas } \\
\text { da gestão } \\
\text { do saneament } \\
\text { o básico no } \\
\text { Brasil: } \\
\text { prestação } \\
\text { indireta e } \\
\text { deficiências } \\
\text { setoriais }\end{array}$ & $\begin{array}{l}\text { https://bityli.co } \\
\text { m/v3MF6 }\end{array}$ & 01/07/2018 & $\begin{array}{l}\text { Por meio do presente artigo, } \\
\text { buscou-se apresentar os } \\
\text { acertos e os desacertos da } \\
\text { atual política pública de } \\
\text { saneamento básico no Brasil, } \\
\text { notadamente ante o cotejo da } \\
\text { perspectiva histórica de } \\
\text { prestação do serviço público e } \\
\text { a transformação dos modelos } \\
\text { de gestão administrativa. } \\
\text { Demonstrou-se que o Brasil } \\
\text { é, por determinação } \\
\text { constitucional, um Estado } \\
\text { Democrático e Social de } \\
\text { Direito, que deve equalizar o } \\
\text { sistema capitalista e a a } \\
\text { garantia dos direitos } \\
\text { fundamentais à cidadania. } \\
\text { Dentre os direitos }\end{array}$ \\
\hline
\end{tabular}




\begin{tabular}{|l|l|l|l|}
\hline & & & $\begin{array}{l}\text { fundamentais, os direitos } \\
\text { sociais, principalmente, têm } \\
\text { por objeto as políticas } \\
\text { públicas, que se caracterizam } \\
\text { por um conjunto de } \\
\text { programas estatais voltados a } \\
\text { uma finalidade } \\
\text { constitucionalmente pré- } \\
\text { determinada. [...] }\end{array}$ \\
\hline
\end{tabular}

Fonte: elaborada pelos autores.

Após o preenchimento do Quadro 3, utilizam-se as conclusões dos artigos para a realização da análise por meio da frequência de palavras, que originou a nuvem de palavras (Figura 1). Para a criação da nuvem foi utilizada a Plataforma online WordArt. Esta ferramenta agrupa e organiza graficamente as palavras-chave evidenciando-as as mais frequentes e que, portanto, deu subsídio para confecção das categorias de discussões.

Por meio da Figura 1, foi possível observar que as palavras em evidência na nuvem pertencem às categorias desenvolvidas a partir da análise de conteúdo de Bardin. Todas as categorias derivam da sua frequência (Tabela 1), que diz respeito ao seu quadro referencial. Em consonância ao objetivo deste trabalho, optou-se por descrever as palavras que apresentaram frequência total no texto e, a partir de seus sentidos nos campos textuais, tinham maior relevância para as representações sociais sobre a influência da relação entre saneamento básico e saúde pública no combate à disseminação do covid-19, como apresentado na Figura 1. 
Figura 1 - Nuvem de palavras criada com base nas conclusões dos trabalhos listados no Quadro 3.

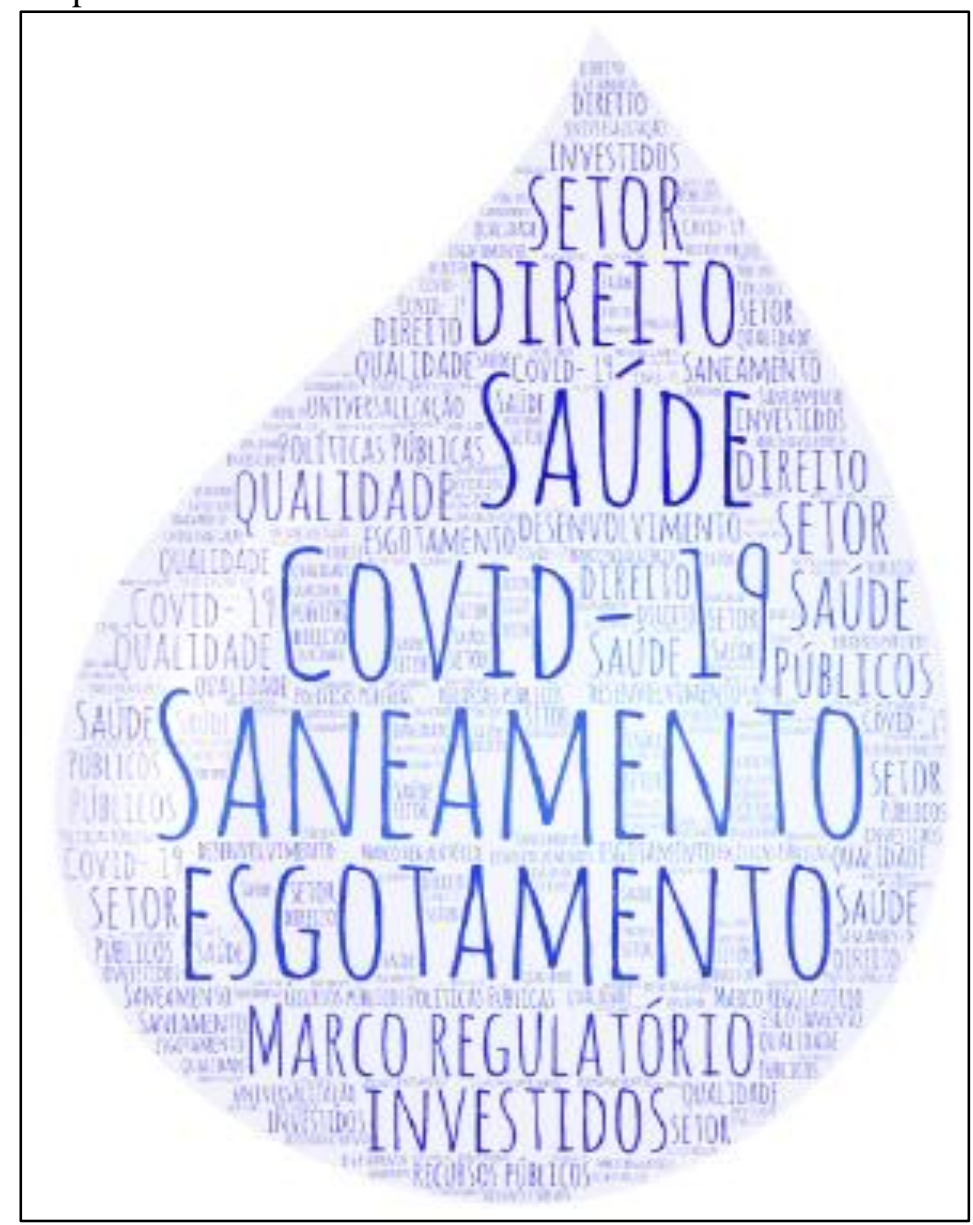

Fonte: elaborada pelos autores.

Tabela 1: Frequência das palavras presentes nos textos publicados na Plataforma Periódico CAPES

\begin{tabular}{l|c|c}
\hline \multicolumn{1}{c|}{ PALAVRAS } & FREQUÊNCIA & CATEGORIAS \\
\hline Saneamento & 20 & 3 \\
\hline Esgotamento & 18 & 2 \\
\hline Covid-19 & 14 & 3 \\
\hline Saúde & 10 & 1 \\
\hline Marco Regulatório & 8 & 3 \\
\hline Direito & 8 & 2 \\
\hline Investidos & 8 & 3 \\
\hline Qualidade & 8 & 3 \\
\hline Setor & 8 & 2 \\
\hline Políticas Públicas & 7 & 3 \\
\hline Desenvolvimento & 7 & 3 \\
\hline Recursos Públicos & 6 & 2 \\
\hline Universalização & 3 & \\
\hline
\end{tabular}

Fonte: elaborada pelos autores. 


\section{DISCUSSÕES}

As categorias de discussão abaixo, oriundas da análise das frequências das palavras (Tabela 1) e da evidência dessas diante da nuvem (Figura 1), assim como, da análise técnica das temáticas abordadas nos artigos selecionados e dispostos no Quadro 3, deram subsídio para discussões pertinentes a temática central do artigo. Abaixo seguem as 3 (três) categorias elaboradas.

\section{Histórico do Saneamento Básico no Brasil}

Após um longo período de debates, a Lei $n^{\circ} 11.445 / 2007$, que estabelece diretrizes nacionais para o saneamento básico no Brasil, entrou oficialmente em vigor em 22/02/2007, regulando um setor que apesar de ser de suma importância permanecia sem regulação específica. Dentre os diversos setores da infraestrutura, as instalações de saneamento básico apresentam características que ajudam a explicar a demora no estabelecimento de um marco regulatório nas áreas jurídica e econômica. Porém, para entendê-los, é interessante considerar a história do Brasil na prestação de serviços básicos de saúde (PEREIRA 2015).

Na década de 1930, quando foram criados os Ministérios da educação e da saúde pública pelo constituinte da época, o serviço de saneamento era prestado diretamente pelos municípios. Na década de 40 foi criada a fundação SESP e houve várias críticas ao modelo de gestão pela administração direta dos Municípios muito em função de uma política tarifária que era deficitária na época e como solução foi criados na década de 1950 os sites sistemas autônomos de água e esgotos na forma de Autarquia Municipal sobre responsabilidade Nacional do SESP e controlada pelos municípios. Já na década de 1960, a SUDENE e posteriormente $\mathrm{BNH}$ começaram a financiar um novo modelo de gestão com a criação das Companhias Estaduais de saneamento básico Segundo Galvão Júnior (2009), a configuração atual da secretaria teve início na década de 1970, quando o governo federal formulou o Plano Nacional de Saneamento Básico PLANASA. Antes disso, os municípios forneciam serviços separadamente. No entanto, os benefícios proporcionados pelo PLANASA estimularam a constituição das Empresas Nacionais de Saneamento Básico (CESB), que passaram a prestar serviços de saneamento básico em grande parte do país (SANTOS, 2018). 
No entanto, a Constituição Federal de 1988 questionou a real titularidade dos serviços básicos de saúde ao conceder aos municípios a capacidade de organizar e prestar serviços públicos de interesse local diretamente ou sob regime de concessão ou licenciamento. Esse dispositivo constitucional tem gerado discussões entre municípios e estados sobre a titularidade e a capacidade de prestação dos serviços básicos de saúde, a discussão tornou-se um dos maiores obstáculos para a aprovação de qualquer projeto de lei que se converta em marco regulatório do setor (SILVA, 2018).

Em 2003, no governo de Lula, iniciouse um intenso processo de reestruturação institucional do setor que se materializou na criação do Ministério das Cidades, que visa integrar políticas relacionadas ao desenvolvimento da cidade. Ele é responsável por propor um novo marco regulatório de saúde e apresentar um projeto de lei à Câmara dos Representantes para votação. Este projeto propõe inovações importantes para a indústria. Entre eles, o novo instrumento da gestão, subordinada a uma agência reguladora, estabelecendo uma agência de controle universitário e fundos federais. É possível perceber que a política pública de saneamento é, acima de tudo, afetada por atores, interesses e instituições que permitiriam explicar o baixo desempenho observado nas últimas décadas (SOUZA, 2016).

"Em 2020, o Comitê das Nações Unidas sobre os Direitos Econômicos, Sociais e Culturais elaborou o Comentário Geral no 15 sobre o direito humano à água. Segundo este comentário o direito à água se enquadra no direito a uma vida com qualidade e está intimamente relacionado com o direito à saúde, alimentação e moradia digna, previstos no Tratado Internacional sobre Direitos Econômicos, Sociais e Culturais. O comentário também estabelece que o acesso ao esgotamento sanitário é essencial para que o direito à água seja atingido." (SILVA, 2018).

\section{Relação do COVID-19 com o Saneamento e as Desigualdades Sociais}

A COVID-19 é uma doença infecciosa que faz com que o coronavírus SARS-CoV2 se torne seu patógeno. Pesquisas científicas apontam que a disseminação do COVID-19 de pessoa para pessoa ocorre principalmente pela via respiratória, gotículas emitidas quando a pessoa infectada tosse ou espirra e pessoas saudáveis entram em contato com superfícies e objetos contaminados. Dependendo do material e / ou composição da superfície, pode permanecer por um período de tempo (SOUZA, 2020).

Porém, nos últimos meses, alguns estudos nacionais e internacionais foram publicados, cujos resultados mostram que o material genético do novo coronavírus está 
presente nas fezes, amostras de urina e de esgoto sanitário de pessoas infectadas (com ou sem sintomas). Portanto, esses estudos destacam os novos desafios que os países precisam reconhecer e enfrentar (MACHADO, 2020).

Embora a OMS (Organização Mundial da Saúde) não tenha declarado que a via fecal-oral não é uma das principais formas de disseminação da COVID-19, o princípio da precaução ainda deve ser utilizado para discutir a possibilidade de que essa via esteja na pior pandemia deste século. Quanto ao princípio da precaução, uma vez que as consequências ou reações de certas ações não são totalmente claras no ambiente, espaço e tempo, devem ser tomadas as medidas necessárias para evitar danos (riscos) futuros ao ambiente e à saúde. Portanto, será importante realizar ações de monitoramento dos sistemas de esgotamento sanitário, principalmente em países onde os casos estão aumentando rapidamente, como o Brasil (SOUZA, 2020).

Na periferia, o conflito no combate ao vírus se manifesta nas políticas de moradia ineficientes dos moradores de rua, segurança alimentar e problemas de saneamento básico, que afetam também os moradores do entorno, que carecem diariamente de água.
Em entrevista para Borezzi (2020), Gisele Martins, jornalista e moradora do Morro da Maré falou que:

"[...] Como garantir medidas de higiene, como lavar as mãos a cada duas horas, se muitas favelas não tem água? [...] E se falta dinheiro para alimentação, como comprar álcool em gel ou álcool 70\%, quando se sabe que, em tempos de pandemia uma embalagem de produto chega a ser vendido por R\$ 15?"

Débora Noal, psicóloga sanitarista diz que:

\begin{abstract}
"Lidar com as desigualdades é o maior desafio da pandemia [...] enquanto para uma parcela da sociedade a preocupação é com o crescimento da curva de contágio pelo vírus, as pessoas que vivem na rua se preocupa muito mais com a sobrevivência no presente."
\end{abstract}

No Brasil, os gestores federais, estaduais e municipais podem cogitar o monitoramento de esgoto, pois a coleta de esgoto é um serviço existente no país. Porém, mesmo que o país tenha o "Plano Nacional de Saúde" (PLANSAB), deve-se estar atento às limitações de todos os municípios, regiões e regiões em termos de cobertura ideal, que se refere ao processo de universalização desses serviços. De acordo com o Sistema Nacional de Informações sobre Saneamento (SNIS), nas áreas urbanas do Brasil, especialmente na região Sudeste, o percentual médio de serviços 
prestados por redes coletoras de esgoto é de $60,9 \%$ e a média é de $83,7 \%$. Em relação ao tratamento de esgoto, segundo observações, o índice médio do país é estimado em $46,3 \%$ do esgoto e 74,5\% do coletado (MOHARA, 2018).

Porém, é fundamental que o Estado amplie o sistema de tratamento de esgoto, inclusive o direito à água de qualidade, e garanta o direito da população a melhores condições de vida, o que afeta diretamente a saúde. Vale lembrar que, para cada $\mathrm{R} \$$ 1,00 investido em saneamento, pode-se economizar R\$ 4,00. Portanto, a consideração do monitoramento do sistema de esgoto contempla também ações de saúde coletiva, avaliando as peculiaridades do território e sua dinâmica populacional e, ao mesmo tempo, considerando o controle social como instrumento de garantia do saneamento e do direito à água (SOUZA, 2020).

\section{Relação entre Saúde Pública e Saneamento Básico}

Para Santos (2018) o saneamento ambiental é compreendido como um conjunto de ações para promover e garantir o bem-estar e a segurança da população e a geração de ruído por meio de rede de tratamento de esgoto, abastecimento de água, coleta e disposição final de resíduos, drenagem e controle da poluição atmosférica. E ainda afirma que:

\begin{abstract}
"Além de consubstanciar melhorias no quadro sanitário e de saúde da população, condições adequadas de saneamento contribuem para a redução de prejuízos econômicos nos cofres públicos brasileiros que ocorrem devido à destinação de recursos para o combate de doenças evitáveis, gerados por doenças infecciosas, parasitárias e transmitidos principalmente por veiculação hídrica".
\end{abstract}

A falta ou falta de instalações de saneamento básico pode ter um impacto negativo na saúde das pessoas. No Brasil, a gestão, a sistematização e a disponibilização das informações relacionadas ao saneamento básico ambiental são realizadas pelo Sistema Nacional de Informações sobre Saneamento (SNIS), que é vinculado à Secretaria Nacional de Saneamento do Ministério do Desenvolvimento Regional e ele próprio um banco. Dados sobre os quatro componentes do saneamento básico em nível municipal, estadual e nacional, a saber: abastecimento de água, esgoto doméstico, gestão e drenagem de resíduos sólidos urbanos e gestão de águas pluviais urbanas (AQUINO, 2020).

De acordo com o último levantamento do SNIS e dados de 2018, estima-se que $16,38 \%$ da população brasileira média não pode usar o sistema público de abastecimento de água. Principalmente no Norte, a proporção é de 42,90\%. Quanto à 
proporção da população sem acesso à rede pública de coleta de esgoto (inclusive uso de rede de tratamento de esgoto), a média nacional é de 46,85\% (SNIS, 2020).

Existe uma relação extremamente estreita e estreita entre saúde e saúde pública. É preciso ressaltar que a saúde é a base de todo o sistema de saúde de um país. A saúde pública está intimamente relacionada às instalações de saneamento. $\mathrm{O}$ aumento das doenças infecciosas e infecciosas é diretamente proporcional à falta de instalações sanitárias e vice-versa. A ocorrência de doenças infecciosas que levam à redução da produtividade, aumento dos custos e aumento das despesas médicas está totalmente relacionada à existência de saneamento básico (FARIAS, 2020).

Se for feito mais investimentos em saúde, as pessoas vão poder fazer um

\section{CONCLUSÕES}

É possível perceber que a falta de saneamento básico nas regiões mais pobres, ocasiona o aumento da COVID-19 nessas áreas, fazendo com que os gastos dos cofres públicos aumentem com o tratamento de mais pessoas contaminadas.

Neste contexto foi demonstrado que os locais mais carentes do território brasileiro são as partes periféricas, no qual sofrem com a falta de esgotamento sanitário, trabalho de saúde com mais saúde, vão ter mais poder, e com essa doença vão diminuir as faltas e faltas. A prevenção é mais econômica e o trabalho mais significativo, pois além de deixar dinheiro para outros investimentos, também pode permitir que pessoas mais saudáveis tenham melhor qualidade de vida (MOHARA, 2018).

Portanto, penso novamente que as instalações de saneamento básico são a plataforma básica e essencial para o desenvolvimento do país. Se você não investe em saneamento básico, não faz sentido ter um país rico com alta produção agrícola e industrial. Devido à falta de saneamento básico, todo o dinheiro e lucros que o país ganhou com as exportações e produção, são perdidos (AQUINO, 2020).

tornando assim mais vulneráveis para a disseminação de doenças.

Como o vazio na definição da titularidade da Lei $\mathrm{n}^{\circ} 11.445$ prejudica diretamente a população das regiões mais carentes onde as verbas públicas não são diretamente direcionadas para o saneamento básico, a constituição de 88 informa que compete aos municípios organizar e prestar os serviços públicos de interesse local. 
Por fim, identificou-se que é necessária a atuação de políticas públicas que buscam expandir os serviços de saneamento, essencialmente para as localidades com

\section{REFERÊNCIAS}

AQUINO, Davi Santiago. Influência do acesso a saneamento básico na incidência e na mortalidade por COVID-19: análise de regressão linear múltipla nos estados brasileiros. Disponível em: <https://bityli.com/530yN>. Acesso em: $01 / 11 / 2020$

BORCEZI, Daniela. Vulneráveis.

Disponível em:

<https://bityli.com/QBzTs>. Acesso em: 28/10/2020.

DA SILVEIRA, Lucia Teresa Côrtes; DE OLIVEIRA, Alexandre Barbosa. Desafios e estratégias para a organização do setor saúde frente à pandemia de COVID19. Research, Society and Development, v. 9 , n. 8 , p. e543985987-e543985987, 2020.

FARIAS, Luis Arthur Brasil Gadelha; COLARES, Matheus Pessoa; et.al. O papel da atenção primária no combate ao Covid-19: impacto na saúde pública e perspectivas futuras. Disponível em: < https://bityli.com/tIw3G>. Acesso em: 01/11/2020.

MACHADO, Michael Ferreira; QUIRÍNIO, Túlio Romério Lopes; Et.al. Vigilância em Saúde em tempos de pandemia: análise dos planos de contingência dos estados do Nordeste. Disponível em: < https://bityli.com/9hhRc>. Acesso em: 28/10/2020. situações mais precárias, para assim evitar a disseminação da COVID-19 e de outras doenças de veiculação hídrica.

MENEZES, Paulo Renato. A Lei 11.445: o novo marco regulatório do saneamento no Brasil e seu impacto nas empresas públicas de água e esgoto: um estudo de caso. 2014.

NOHARA, Irene Patrícia; POSTAL, Júnior Jairo. Perspectivas da gestão do saneamento básico no Brasil: prestação indireta e deficiências setoriais. Disponível em: < https://bityli.com/v3MF6>. Acesso em: 28/10/2020.

PÊGO, Bolívar et al. Pandemia e fronteiras brasileiras: análise da evolução da Covid-19 e proposições. 2020.

PEREIRA, Tatiana Santana Timóteo; HELLER, Léo. Planos municipais de saneamento básico: avaliação de 18 casos brasileiros. Disponível em: < https://bityli.com/Z2Uh1>. Acesso em: 02/11/2020.

QUINTSLR ${ }^{1}$, Suyá; BRITTO, Ana Lúcia; DIAS, Mariana. Coronavírus: reflexões acerca da pandemia global e sua relação com o direito à água e ao esgotamento sanitário. Observatório das metrópoles, 2020.

SANTOS, Fernanda Flores Silva dos; FILHO, José Daltro; et.al. desenvolvimento do saneamento básico no Brasil e as consequências para a saúde pública. Disponível em: $<$ https://bityli.com/cK3hp $>$. Acesso em: 28/10/2010. 